\title{
Gobernabilidad \\ para el desarrollo humano sostenible en El Salvador
}

José Luis Lovo-Castelar'

Recibido: 20/11/2014 - Aceptado: 19/12/2014

\section{Resumen}

La gobernabilidad de la República requiere de una base humana organizada que configure la expresión social dinámica y actuante del pueblo en el esfuerzo nacional por el desarrollo humano sostenible. Entre el hombre, individualmente considerado, y el Estado, como figura totalizante, surgen las organizaciones intermedias que permiten conjuntar las fuerzas individuales en defensa de sus intereses de grupo o de sus objetivos particulares, constituyéndose en una instancia de poder social o grupo de presión, de servicio, promoción, defensa o ayuda mutua. El Estado descansa en los esfuerzos de las organizaciones y tiene un sistema de controles y registros legales sobre una gama de ellas. En este artículo de opinión se presenta una serie de planteamientos y desafíos en los nuevos entornos, en un contexto que exige decisiones adecuadas.

\section{Palabras clave}

Gobernabilidad, organizaciones no gubernamentales, Estado, desafíos del entorno, derechos humanos.

\section{Abstract}

The governability of the Republic requires an organized human foundation to set up the social dynamic and active expression of the people in a national effort for sustainable human development.

Between man, individually speaking, and the State, as a whole figure, there are intermediate organizations that allow for the combination of individual forces in defense of their group interests or their particular objectives, thus constituting an instance of social power or pressure group; a group of service, promotion, defense or mutual aid.

The State relies on the efforts of organizations and it possesses a system of legal checks and records over a range of these organizations. This article presents a series of proposals and approaches in new environments within a context that requires proper decision-making.

\section{Keywords}

Governability, non-governmental organizations, State, environmental challenges, human rights.

Abogado y notario, graduado de la Universidad de El Salvador. Doctor en Jurisprudencia y Ciencias Sociales con estudios en Derecho Internacional Público en la Comisión de Derecho Internacional de las Naciones Unidas (Ginebra, Suiza). Diplomático. Ex funcionario del Ministerio de Relaciones Exteriores y del Servicio Exterior. Delegado ante las Naciones Unidas con sede en Nueva York y Representante permanente en Ginebra, Jefe de Misión ante la Oficina Europea de las Naciones Unidas y los Organismos Internacionales, con sede en Ginebra. Autor del libro "Prolegómenos del Derecho del Mar", publicado, en segunda edición, por la Corte Suprema de Justicia. En la actualidad se desempeña como Socio-Director del Instituto Iberoamericano de Derecho Constitucional, sección El Salvador, miembro de número de la Academia Salvadoreña de la Historia, Directivo de la Academia de Historia Militar de El Salvador, entre otros cargos. 


\section{Gremios y asociaciones}

\section{Frente al reto de gobernabilidad}

Los gremios y asociaciones son parte del universo de organizaciones que se constituyen en el Estado como producto de la vocación gregaria del hombre; de la necesidad o utilidad de la unión para adquirir fuerza y viabilidad en sus objetivos. Esta realidad sociológica encuentra en el derecho su fundamentación, específicamente en el principio de la libertad de asociación, que la Constitución de la República de El Salvador contempla en su Art. 7 y desarrolla una serie de disposiciones relativas a formas particulares de organización, como son los sindicatos (Art. 47), los partidos políticos (Art. 72), las corporaciones o fundaciones civiles o eclesiásticas (Art. 108), las asociaciones de tipo económico (Art. 113), las asociaciones cooperativas (Art. 114), las universidades e institutos tecnológicos (Art. 61), los gremios médico, odontológico, químico farmacéutico, médico veterinario (Art. 68), el gremio de abogados (Art.186), las municipalidades (Art. 202) y otros que encuentran cabida dentro de la normativa constitucional. La gestión eficiente del gobierno no solo presupone la existencia de los gremios y asociaciones, sino que requiere de su respaldo y participación en el propósito de lograr el desarrollo humano sostenible.

La categoría de Organizaciones no Gubernamentales (ONG) únicamente comprende las entidades privadas. Sin embargo, en la perspectiva general del tópico de análisis, se comprenden todas las entidades intermedias, inclusive las estatales (universidades y municipalidades, etc.). También son entidades intermedias las constituidas en el campo mercantil.

Identifiquemos y destaquemos la relevancia de algunas: a) organizaciones campesinas, asociaciones para el desarrollo comunal, cooperativas agrarias en la lucha por mejorar sus condiciones de vida; b) asociaciones cívicas, culturales, religiosas, en el enaltecimiento de valores espirituales y patrióticos; c) organizaciones de trabajadores, empleados, profesionales liberales, profesores, estudiantes en la defensa y promoción de sus derechos; d) sindicatos de trabajadores, en la lucha por superar las condiciones de trabajo y prestaciones del obrero; e) organizaciones de empleadores, asociaciones empresariales, industriales, comerciantes, banqueros, etc., en la defensa de sus intereses sectoriales y como grupos de presión; f) partidos políticos, en la lucha por obtener el poder del Estado, en función de sus propósitos ideológicos; g) organizaciones de derechos humanos, incluyendo las organizaciones de mujeres, ecológicas, de excombatientes, lisiados de guerra, que se pronuncian por la igualdad, la justicia o causas específicas; h) universidades, fundaciones 0 centros de estudio de investigación científica, tecnológica, cultural, jurídica, etc.; i) clubes de servicio y recreación; j) asociaciones deportivas; k) asociaciones sociales (de excompañeros de estudios, por ejemplo); I) juntas de vecinos o colonias, para mejorar sus ámbitos de residencia; todas ellas constituyen una suerte de engranaje en el que se desenvuelve la vida social, se manifiestan voluntades colectivas y se actúa en pos de intereses particulares, en una interacción extraordinaria.

La gobernabilidad del país recoge la expresión inagotable del pueblo a través de sus organizaciones, que contribuyen de una y mil maneras al quehacer nacional, por tanto, son factor decisivo para la realización de objetivos de desarrollo humano. El pueblo organizado llega a constituirse en una de las columnas del poder del Estado. En nuestra reciente historia, las llamadas organizaciones de masas jugaron un papel impresionante. Actualmente la esfera religiosa tiene un papel importantísimo por medio de las redes de grupos de oración, movimientos conyugales, cursillistas, evangelizadores, etc.

La vida y efectividad de estas organizaciones depende de la voluntad, mística y aporte personal de sus miembros, así como de la capacidad de sus líderes. Anteponiéndose a estas entidades, como célula social fundamental de la sociedad, se encuentra la familia, forjadora de valores y cualidades en cada individuo, donde se dan los primeros pasos, configurando núcleos de solidaridad arraigada.

\section{Frente al reto del desarrollo sostenible}

El desarrollo humano sostenible debe tener en debida consideración la existencia de los gremios y asociaciones, de cuya participación organizada en programas estatales, o en todo género de actividades, depende el logro de metas o la solución de problemas generales o locales. Un plan que no tome en consideración el poder y las posibilidades de las entidades sociales involucradas o afectadas está condenado al fracaso o a obtener magros resultados. Las entidades intermedias son la presencia organizada de uno de los elementos del Estado, la población, que en su connotación política se identifica como el pueblo, el titular de la soberanía del Estado.

Las organizaciones no gubernamentales, que configuran la sociedad civil, tienden a organizarse para demandar transformaciones en todos los campos de la vida nacional, impulsando el curso del desenvolvimiento histórico del país. No solo contribuyen al desarrollo de sus propias finalidades, sino 
que se proyectan vigorizantemente en todo el escenario nacional y son copartícipes del esfuerzo de gobernabilidad.

\section{Referente hacia la seguridad ciudadana y jurídica}

La tendencia humana a formar grupos y asociaciones es un reflejo de la aspiración natural de lograr mayor certeza en la realización de sus derechos y objetivos, necesidad que se agiganta frente a la dimensión desproporcionada entre el poder individual, naturalmente limitado, frente al que se atribuye el Estado con sus amplios recursos y medios coercitivos. La idea de que la unión hace la fuerza se vincula directamente a esta noción. En el grupo, el hombre busca multiplicar sus posibilidades de presencia y acción. Así, se pueden visualizar las organizaciones como medios válidos para reforzar la seguridad ciudadana y la seguridad jurídica, lo que podrá hacerse patente según la finalidad o potencialidades de cada ente constituido.

Cada asociación constituye, en materia de seguridad, un mecanismo de defensa frente a las restantes organizaciones o grupos que pudieran contraponérsele por razones de hecho o de derecho; y, como tales, encuentran mayores posibilidades para que sus posiciones sean alcanzadas. La expresión colectiva de la acción otorga al empeño en marcha una fuerte connotación democrática, y le proporciona mayor impacto a las demandas ciudadanas.

\section{Marco de los derechos humanos}

Además de que las asociaciones son una expresión del derecho humano a asociarse, constituyen medios que permiten defender y promocionar los derechos individuales y colectivos con mayores niveles de proyección y representatividad que los individuos aislados. En tal sentido, las asociaciones son un cauce para la manifestación de pretensiones y aspiraciones populares de carácter reivindicativo en el ámbito político social. Es en el contexto de las luchas sociales donde se han ido reconociendo y cristalizando los derechos de los individuos. El fortalecimiento de los organismos que forman la sociedad civil coadyuva a la consolidación del Estado de Derecho, que ostenta el respeto y vigencia de los derechos humanos como uno de sus elementos primordiales.

\section{Perspectivas de género y participación}

El fenómeno de la organización femenina es reciente en sus manifestaciones de movimiento reivindicatorio de género. Las organizaciones femeninas tradicionales eran predominantemente de orientación religiosa o propia de su restringida vida social. El movimiento de mujeres no ha tenido todavía el poder suficiente para hacer efectivas sus aspiraciones o para enfrentarse a prácticas discriminatorias o vejatorias subsistentes. La marginación de la mujer, sin embargo, puede encontrar respuestas apropiadas en el reclamo directo de ellas mismas, a través de sus propias organizaciones.

Las organizaciones femeninas van forjando conciencia colectiva de los derechos que les son conculcados y de la importancia de su participación para constituirse en una fuerza social poderosa. Dentro de las organizaciones femeninas, mencionamos las siguientes: a) Asociación de Mujeres Campesinas (AMSC); b) Instituto de Investigación de la Mujer (IDI-Mujer); c) Asociación de Mujeres Salvadoreñas (Ademusa); d) Movimiento de Mujeres "Mélida Anaya Montes" (MAM); Asociación de Mujeres por la Dignidad y la Vida (Dignas); e) Organización Empresarial Femenina de El Salvador (OEF); f) Asociación de Mujeres para la Democracia "Lil Milagro Ramírez" (LMR); g) Mujeres Universitarias de El Salvador (Mues); h) Patronato Pro Integración de la Mujer al Desarrollo (Pimude); h) Asociación de Mujeres Jueces de El Salvador (Amjes); i) Asociación de Mujeres Abogadas (ASA), etc. Esta cantidad de organizaciones demuestra la inquietud y voluntad femeninas de incrementar y superar su papel en esta sociedad.

Por otra parte, hay que apuntar que la participación de las mujeres en las organizaciones, y gremios en general, se ha incrementado, alcanzando puestos de dirección, con lo que se van superando la casi exclusividad de la presencia masculina en movimientos organizados.

Aun así, el importante papel de la mujer como proveedora de ingresos para el grupo familiar no encuentra equilibrio con las oportunidades de ocupar posiciones de dirección en organizaciones públicas y privadas, en donde generalmente se encuentra relevada de los niveles superiores de mando.

En las organizaciones políticas del país, la mujer está aumentando sus niveles de presencia. Lo mismo podría indicarse en lo que se refiere a sindicatos, gremios y asociaciones profesionales.

\section{Situación actual}

La variedad y extensión de los gremios y asociaciones en el país determinan que estas constituyen un elemento indispensable en la gobernabilidad democrática, para el desarrollo humano sostenible. 
El papel histórico de las organizaciones en el proceso de democratización, sin embargo, es en general menor de lo deseable en materia de participación, salvo aquellas constituidas como entidades políticas o grupos de presión y que disponen de amplios recursos humanos y económicos, que logran trascender.

La falta de colegiación profesional obligatoria es causa de que las organizaciones formadas por profesionistas liberales tengan limitaciones en la cantidad de sus integrantes, restringiendo su poder de influencia y aportes a la sociedad.

\section{El frente externo}

\section{Frente al reto de gobernabilidad}

El reto de gobernabilidad en lo referente al ámbito internacional lo circunscribimos a los ámbitos político, económico y jurídico. Conceptuamos el desafío en la necesidad de enfrentar un conjunto de condicionantes foráneas que afectan las potencialidades del Estado para alcanzar el desarrollo humano sostenible. Existen grandes limitantes internas derivadas de la situación general y escasez de recursos del país. A ello se suman un conjunto de dificultades de la política exterior y una pobre perspectiva de penetración del sector nacional a un mundo globalizado.

En el ámbito político, en primer lugar, el país necesita mantener relaciones de alto nivel, que se traduzcan en respaldos efectivos con los Estados Unidos de América, que se adviertan en un apoyo efectivo a la política de integración regional; en concretizar una apertura comercial a los productos centroamericanos; en mantener flujos de cooperación técnica y financiera, y en manejar el problema de los migrantes salvadoreños en aquel país de manera tal que no se produzcan expulsiones a gran escala, que agravarían la situación social del país, en desmedro en los proyectos de desarrollo humano sostenible.

La iniciativa de transformar el proceso de integración socioeconómica en un esquema de unificación comunitaria, con sentido político, es de orden prioritario frente a las exigencias que impone el proceso mundial de globalización, pero en sus perspectivas son muy inciertas en razón de las reservas y oposiciones que se formulan desde un principio por parte de sectores poderosos en Guatemala y Costa Rica, y de la latente conflictividad con Honduras.

La situación conflictiva con Honduras no encuentra visos de solución, dado que el proceso de demarcación fronteriza se dificulta por los contenidos del fallo de la Haya de 1992; por los problemas de derechos humanos de los pobladores salvadoreños en zonas atribuidas a ese país, y por la controversia sobre los espacios marítimos en el océano Pacífico y en el golfo de Fonseca.

En el ámbito económico-comercial, la globalización se ve con preocupación por la imposibilidad de competir de los productores locales frente al poderío y calidad de la oferta exterior en el mercado nacional y viceversa... No hay competitividad plausible, pero el país no puede sustraerse de esta corriente mundial por su dependencia del sector externo.

La globalización afecta directamente la gobernabilidad, al trasladar proyectos de desarrollo económico neoliberales a ultranza, privatizaciones impopulares y programas de modernización que no encajan, por fundamentarse en esquemas impuestos o importados de difícil asimilación local, y porque agravan situaciones de marginación de vastos sectores de la población. El poderío de las empresas transnacionales y el flujo de capitales de todo origen que penetra al país no solo afectan a empresarios locales e impacta el sistema financiero, sino que, según experiencias vistas, ponen en jaque la soberanía nacional.

La globalización implica suscribir una multitud de acuerdos internacionales, tanto entre Estados como con organismos internacionales financieros, que imponen sus términos sin dejar mayores alternativas.

\section{Frente al desarrollo humano sostenible}

Las negociaciones de tratados internacionales de carácter económico, comercial o integracionista requieren de expertos nacionales de alto nivel y experiencia, de lineamientos precisos y de una determinación clara, política, de los intereses y objetivos nacionales, y contar con un amplio respaldo de las principales fuerzas del país, lo que pareciera no estar consumado ni es de fácil concertación.

Los organismos internacionales no deben suplir las responsabilidades del gobierno, si se desea que tenga éxito la estrategia hacia el desarrollo humano sostenible, ya que con la finalización de los programas de cooperación, tarde o temprano, se produce un vacío irremplazable, y lo ganado trabajosamente se pierde con facilidad. En consecuencia, simultáneamente el país debe fortalecer su papel internacional y la preparación de sus expertos, capitalizando la cooperación que se recibe en la formación 
de cuadros y en el diseño de estrategias y planes que pueda ejecutar por sí mismo, que guarden continuidad por encima de los cambios de gobernantes y de partidos en el poder.

A la vez que la política exterior negociadora logre que los convenios y las alianzas económicas se materialicen, será necesario que el gobierno adopte las correlativas medidas internas que aquellos presuponen o exigen, pero eso sí, sin menoscabar el bienestar de las personas, que deben mantenerse en el centro de la preocupación de los representantes y administradores estatales.

\section{Referentes hacia la seguridad ciudadana y jurídica}

El tema de la seguridad ciudadana y jurídica es propio del orden interno del Estado, y el reto de gobernabilidad frente a estas áreas se vincula a la capacidad de prevención y represión de hechos contrarios a la ley, el orden público y específicamente a la integridad y cúmulo de derechos de las personas. Asimismo, en el referente de la seguridad jurídica, el tema concierne a la existencia de un régimen de legalidad que proteja los derechos subjetivos de las personas y asegure la proyección de las normas como sistema de garantía que dé certidumbre sobre la capacidad de uso y goce de tales derechos. En cuanto al tema de seguridad ciudadana, el enfoque internacional comprende las posibilidades de obtener asistencia externa para la formación de nuestros agentes responsables, pero además en la concertación de acuerdos de cooperación en la persecución de los delincuentes; en la represión de delitos de carácter internacional o del tracto sucesivo. De manera especial, es imprescindible que se refuerce el sistema de coordinación de fuerzas policiales para la lucha contra el narcotráfico, que se ha vuelto un flagelo de la humanidad. Otro campo de cooperación es el de la lucha contra el tráfico internacional de vehículos robados.

El campo de la seguridad jurídica, en relación con el ámbito internacional, puede apreciarse en la importancia de la normativa del derecho internacional privado que ampara los derechos subjetivos puestos en peligro en operaciones o actividades en país extranjero, a cuyo propósito es relevante que el país estudie la posibilidad de ratificar convenciones modernas sobre la materia. En el ámbito de la propiedad intelectual, es evidente que el esfuerzo internacional que se realiza desde la Organización Mundial de la Propiedad Intelectual (Ompi), con sede en Ginebra, es de considerable importancia, a cuyo propósito debería de participar activamente en las conferencias y actividades de esta entidad. Por tanto, compete al Ministerio de Relaciones Exteriores y a otras instituciones de gobierno en las áreas respectivas determinar los tratados que deberían ratificarse y los organismos en los que habría que incrementar la participación nacional para obtener cooperación y conocimiento sobre los avances que se van obteniendo en ellos y en sus miembros.

\section{Marco de los derechos humanos}

El tema de Derecho internacional de los derechos humanos, como referente de gobernabilidad democrática, comprende numerosos tratados adoptados en el marco de las Naciones Unidas y de la OEA, varios de los cuales han sido ratificados por El Salvador, que está obligado a su cumplimiento, como las leyes de la República, y a rendir los informes que en dichos tratados se señalan a las instancias correspondientes. Estos informes se sujetan a un temario minucioso y a períodos específicos. Delegados de El Salvador se ven en el caso de acudir a las reuniones donde se analiza y responde los cuestionamientos que se hacen. Puesto que el tema de los derechos humanos se subdivide en cuestiones civiles, políticas, sociales, económicas y culturales, ampliándose ahora a temas genéricos, como son los derechos del pueblo a la libre determinación, a la paz, al desarrollo, y otros, denominados de la tercera generación, el examen de los casos por país se prolonga por varios días y requiere de equipos multidisciplinarios bien preparados para someterse a los interrogatorios durante la serie de audiencias que se programan. Este es el caso concreto del Comité de Derechos Humanos, creado en el pacto de derechos civiles y políticos. La referencia tiene el sentido de subrayar la necesidad de disponer de expertos nacionales que actúen en estos foros.

Por otra parte, El Salvador debe llevar un escrupuloso control de las responsabilidades adquiridas al ratificar los tratados, para darles debido cumplimiento. Surgen problemas de interpretación del tratado en relación con la Constitución y las leyes secundarias, en cuya solución se hace necesaria la opinión de expertos en esta materia, que presten la debida asesoría a las instancias políticas. El caso del proyecto de reforma constitucional ampliando la pena de muerte ilustra la anterior aseveración.

Puesto que la vigencia y promoción de los derechos humanos representa un objetivo del Estado y, a la vez, una obligación frente a la comunidad internacional, se perfila como reto de gobernabilidad insoslayable, en cuya respuesta tienen que jugar un papel primordial la Procuraduría para la Defensa de los Derechos Humanos y los organismos no gubernamentales que actúan en este ámbito; entre otros motivos, a fin de impulsar y lograr que la acción de los poderes del Estado, en sus respectivas áreas, sea efectiva y redunde en el desarrollo humano sostenible. 
La noción de desarrollo humano sostenible se enlaza estrechamente con el concepto de derechos humanos en el sentido de que la vigencia y positividad de la legislación sobre estos derechos son el basamento jurídico de aquella, dada la extensión de las materias que comprende y de su imperatividad propia, como normativa de jus cogens.

\section{Perspectivas de género y participación}

La respuesta al reto de gobernabilidad democrática en la perspectiva de género y participación incluye necesariamente consideraciones sobre la realización, en la sociedad, del principio constitucional de igualdad sin distinción de sexo y la aplicación de los tratados que lo incorporan y desarrollan. Puesto que se manifiestan ámbitos discriminatorios de la mujer en nuestro medio, es necesario que se impulsen políticas efectivas para superar la situación que se presenta. En tal sentido, es necesario que se fortalezcan las entidades que propenden hacia este objetivo y que se favorezca su participación al efecto. El desarrollo humano sostenible en relación con el sector femenino de la población, que sobrepasa el $50 \%$ de los habitantes del país, es, de consiguiente, de una magnitud que impone un esfuerzo de alta prioridad en el Estado.

\section{Situación actual}

La atención del reto de gobernabilidad en lo que denominamos el frente externo compete a las responsabilidades del Órgano Ejecutivo y, dentro de este, del Ministerio de Relaciones Exteriores en un primer escalón, el cual, por tanto, debe fortalecer sus equipos e incrementar su papel en función del desarrollo humano sostenible.

Los aspectos jurídicos y diplomáticos de la gestión de Cancillería, en consecuencia, deben de ponderarse a fin de hacerse un diagnóstico adecuado sobre sus limitantes, necesidades, enfoques y prioridades en toda su complejidad.

En el ámbito diplomático internacional, la actividad y presencia de El Salvador es muy baja. Se ha enfrascado en atender los aspectos de la mundialización del comercio, las cumbres presidenciales centroamericanas y los compromisos externos propios y derivados de los Acuerdos de Paz. Por lo demás, se ha puesto atención en los asuntos de la Comisión de Derechos Humanos, en las plenarias de la Asamblea General y en la atención formal de sus relaciones bilaterales tradicionales, sin dejar de mantener la presencia diplomática multilateral en la OEA, ONU-Nueva York-Ginebra y Bruselas.
Estando sobredimensionado en el país el papel de la ONU, y careciendo de una entidad planificadora, se ha generado una serie de dependencias de sus programas de asistencia técnica y cooperación financiera, además del tradicional peso de los Estados Unidos. Así, los asuntos bilaterales y la proyección externa del Estado se están debilitando, inclusive se está descuidando el problema marítimo tradicional con Honduras, al que apenas se da seguimiento, sin tomarse iniciativas o posicionamientos definidos.

La falta de ratificación de la Convención de Viena sobre los Derechos de los Tratados y de la Convención de las Naciones Unidas sobre el Derecho del Mar, de importancia manifiesta, debe de considerarse como un asunto de fondo, que concierne a materias de relevancia indiscutible.

La iniciativa unionista del gobierno de la República abre magníficas posibilidades para el cumplimiento de los objetivos de desarrollo humano sostenible en la región; y en la consecución de este esfuerzo se valora en el contexto del reto de la gobernabilidad.

\section{Desafíos}

1. Fortalecimiento del Ministerio de Relaciones Exteriores y ampliación de su gestión en el objetivo del desarrollo humano sostenible.

2. Elaboración de un plan de política exterior amplio y coherente, que comprenda la definición de objetivos en la defensa de los intereses primarios de la República.

3. Ampliar la participación de El Salvador en foros y conferencias internacionales.

4. Mantener la política centroamericana orientada hacia la creación de una comunidad de Estados en la región.

5. Fortalecer la gestión diplomática bilateral por los Estados Unidos de América y continuar gestiones para concertar soluciones apropiadas en el problema de la ilegalidad de migrantes salvadoreños en dicho país.

6. Revisar la política nacional frente al fenómeno de la globalización, teniendo en consideración la necesidad de que no se afecte negativamente el empeño por el desarrollo humano sostenible.

7. Defender los derechos humanos de los pobladores salvadoreños en zonas objeto de la sentencia de la Corte Internacional de Justicia en el conflicto limítrofe con Honduras y llevar adelante negociaciones que 
permitan la resolución amistosa de las diferencias existentes en cuanto a la demarcación y la determinación de los derechos en el golfo de Fonseca y de los espacios marítimos fuera de este.

8. Llevar adelante estudios sobre tratados internacionales ratificados que establecen compromisos de ejecución y de instrumentos no ratificados, cuyo efecto en el país favorecería el desarrollo humano sostenible.

9. Crear y fortalecer sedes diplomáticas y consulares en países y lugares en que existen grandes núcleos de población de salvadoreños.

10. Gestionar cooperación técnica y financiera internacional en respaldo de programas para el desarrollo humano sostenible.

\section{Burocracia y modernización de la administración estatal}

\section{Frente al reto de gobernabilidad}

La gobernabilidad del país requiere de un órgano ejecutivo caracterizado por una alta capacidad de administración de la cosa pública, con posibilidades ciertas a diseñar y aplicar políticas de Estado eficientes, en el amplio espectro de áreas propias de su mandato constitucional. Este reto se enfrenta a una realidad social-económica-política definida tradicionalmente en el concepto de subdesarrollo, vale decir, significativamente, de un medio de pobreza, incultura generalizada, escasez de recursos, deterioro ecológico alarmante y elevada tasa de crecimiento poblacional, manifestaciones que encabezan una lista abrumadora de temas y problemas atingentes a las responsabilidades del gobierno central.

La paz, la estabilidad política y la democracia están indisolublemente ligadas a la forma en que se responde al reto de la eficacia administrativa.

Se observa carencias para atender adecuadamente este desafío, entre ellas: a) de una agenda nacional que defina rumbos, prioridades y objetivos; b) de políticas que respondan a los graves requerimientos ostensibles a largo, mediano y corto plazo; c) de recursos humanos calificados; d) de asignaciones presupuestarias eficientes; e) de coordinación y cooperación interna centralizada; y f) de dirección coherente y motivadora.

La existencia de un aparato burocrático anquilosado, lento y pesado, dificulta a las autoridades políticas la realización de un buen gobierno, es decir, la debida utilización de los mecanismos institucionales en función de los objetivos planteados en las campañas electorales. En consecuencia, la función administrativa se trata de realizar fijándose prioridades con sentido ideológico en los campos político y económico, con medidas insuficientes y en ocasiones inadecuadas, descuidándose al sector social.

El reto de gobernabilidad se asume bajo el esquema internacional de participación en un mundo globalizado, mediante políticas económicas neoliberales, privatizaciones, apoyo al sector productivo para mejorar su poderío y competitividad externa y, en lo que se refiere al Estado, en el diseño de tareas de modernización, en forma limitada. Los logros en la estabilización y crecimiento económico se proyectan con fragilidad, entre otras razones, por no verse acompañados de avances suficientes en el marco global. Las tendencias recesivas en el sector productivo son motivo de preocupación al cuestionar la efectividad del modelo.

\section{Referentes hacia la seguridad ciudadana y jurídica}

Recientemente se ha hecho público, a escala mundial, que El Salvador ocupa el segundo lugar en la categoría de delincuencia. Aun cuando pongamos en duda esa ubicación, no podemos negar que el fenómeno presenta una gravedad terrible. Las causas que se señalan son principalmente de índole social; entre ellas, los afectos de una fallida reincorporación productiva de los antiguos combatientes y la subcultura guerrista que generó el conflicto; la pobreza e injusticia social; la repatriación masiva desde los Estados Unidos de jóvenes delincuentes; la pérdida de valores y la ansiedad o afán de lucro sencillo generado en la sociedad por diferentes medios.

La inseguridad ciudadana no pudo enfrentarse a su caudalidad por las nuevas fuerzas policiales. Más bien, la casi ausencia de los controles durante la fase de transición y la ulterior inexperiencia de las nuevas autoridades, pese a la asesoría internacional, dejaron espacio para el crecimiento delincuencial.

La inseguridad jurídica en el ámbito administrativo es una realidad cotidiana, atribuible a la corrupción, a las incapacidades y negligencias de supuestos "servidores" públicos. Pese a las buenas intenciones, la lentitud y falta de respuesta a las solicitudes ciudadanas sigue siendo prevaleciente. Los ejemplos de casos personales de experiencias negativas, al acudir a oficinas públicas, son el pane nostrum quotidianum. Valga significar que el problema de los registros está siendo enfrentado con 
nuevos mecanismos, si bien la inseguridad registral es otra cruda realidad.

En materia tributaria, se ha trabajado con bastante fuerza por parte de las autoridades hacendarias, al grado que existen reclamos de persecuciones e injusticias que se extienden en la opinión pública como factor de preocupación.

Los escándalos financieros han evidenciado otros campos de inseguridad jurídica, dado que los controles y supervisiones estatales no funcionan apropiadamente.

Otros motivos de inseguridad son de carácter económico, pues el hombre advierte sus limitaciones en materia de ingresos salariales, frente al desempleo y subempleo, así como en la penuria de las potenciales prestaciones sociales por vejez e incapacidad física para el trabajo. Las incertidumbres en cuanto a las prestaciones y servicios de seguridad social son innegables.

\section{Marco de los derechos humanos}

Como efecto de la paz, El Salvador dejó de estar en el banquillo de los acusados como país violador de los derechos humanos en los foros internacionales.

La creación de la Procuraduría para la Defensa de los Derechos Humanos (PDDH) ha creado un marco institucional que, con todo y sus limitaciones jurídicas y financieras, lleva adelante un trabajo consistente en la materia.

De conformidad con los informes de la PDDH, el mayor número de casos que se reportan son atribuidos a la Policía Nacional Civil, por vejámenes y detenciones ilegales, en el campo de los derechos de la primera generación, es decir de los derechos civiles y políticos. El segundo lugar lo ocupa la administración de justicia, por las violaciones a las normas de debido proceso.

Sin embargo, el área principal donde se advierte el problema de derechos humanos es en los de la segunda generación, vale decir, en los derechos económicos, sociales y culturales. La responsabilidad es atribuible a la administración central, que no lleva adelante políticas efectivas, en la medida suficiente, en las áreas de salud, vivienda, educación y servicios públicos en general.

\section{Perceptivas de género y participación}

Se han puesto en marcha políticas de apoyo y defensa de la mujer que constituyen una puesta de atención en un área escasamente atendida. La Secretaría Nacional de la
Familia y el Instituto Salvadoreño para el Desarrollo de la Mujer enfrentan el reto de promover el papel primordial que a estos les corresponde y de superar su situación de marginalidad y discriminación.

La presencia de la mujer en los altos cargos en el conjunto de instituciones de conforman el Órgano Ejecutivo es numéricamente muy reducida, si bien ya han logrado acceso a puestos ministeriales y jefaturas de entes autónomos. A niveles técnicos y de mandos medios, la mujer ha logrado posiciones de manera regular, en una tendencia positiva.

Las mujeres ocupan la mayoría de cargos secretariales en oficinas públicas, mayoritariamente con remuneraciones bajísimas que las mantienen en situaciones de pobreza, con grandes limitaciones para atender sus necesidades personales y familiares.

\section{Situación actual}

El Gobierno de la República se observa con graves impedimentos para hacer frente al cúmulo de desafíos que requiere la gobernabilidad democrática para el desarrollo humano sostenible, según venimos de apuntar.

Limitaciones derivadas de la estructura económicosocial del país y de la falta de un programa de acciones consistente, como producto directo de los Acuerdos de Paz, incidieron en que estos campos fueran ubicados en segundo nivel, ya que en primer lugar había que atender los compromisos de orden público.

La modernización del Estado, como objetivo definido del actual gobierno, ha obtenido ligeros avances en algunos ministerios e instituciones, pero la burocracia sigue siendo lamentable. Las carencias e ineficiencias institucionales; la falta de agilidad del soporte administrativo; la incompetencia en jefaturas y niveles técnicos; la falta de voluntad de trabajo y sacrificio; y la indisciplina y la corrupción continúan prevaleciendo. Esta generalización, posiblemente excesiva, debe excepcionarse con la existencia de cientos de empleados que hacen gala de la laboriosidad que caracteriza al salvadoreño. Esto no lleva a concluir que los vacíos y problemas apuntados se encuentran en la falta de conocimientos y aplicación de la ciencia de la administración pública para el desarrollo integral, en función de cada individuo.

\section{Desafíos}

1. Robustecer la democracia y la participación, en un pleno desarrollo de los derechos civiles y políticos inalienables del individuo, facilitando el acceso de 
los ciudadanos a las instancias gubernamentales, escuchándolos y brindándoles respuestas.

2. Diseñar y ejecutar políticas que hagan efectivos los derechos económicos y sociales de las personas en el cumplimientos de la obligación constitucional de realizarlos, asumida al recibir los cargos de jefatura del Órgano Ejecutivo.

3. Orientar los esfuerzos para hacer que la administración pública sea ágil y eficiente en el cumplimiento de sus tareas, bajo el propósito de hacer una realidad el desarrollo humano sostenible.

4. Asumir la responsabilidad de llevar adelante las transformaciones necesarias para superar las berreras que se oponen al desarrollo y, en prosecución de ello, modernizar las estructuras internas y las concepciones en que trabajan.

5. Procurar la coordinación, coherencia y cooperación entre las instituciones estatales, para que cumplan efectivamente sus responsabilidades eliminando el derroche de esfuerzos y recursos.

6. Instaurar procedimientos administrativos funcionales y apropiados para el desarrollo de las funciones de gobierno, con el fin de servir a la persona humana, que es el origen y fin del Estado.

7. Ejercer una sana dirección y un liderazgo motivador que cambie las actitudes de negligencia, descuido e irresponsabilidad en los funcionarios y empleados estatales.

8. Mantener programas constantes de capacitación y actualización profesional de los servidores públicos, para el mejor cumplimiento de sus tareas.

9. Promover y lograr una mayor participación del pueblo interesado en la realización de proyectos y en la explotación de sus propios recursos.

\section{Desorden e ineficacia legislativa}

\section{Frente al reto de gobernabilidad}

El reto de gobernabilidad del país, en lo que concierne al Órgano Legislativo, se define principalmente en el cumplimiento de la responsabilidad de emitir leyes que constituyan una respuesta adecuada a las exigencias planteadas en la sociedad para hacer posible el desarrollo humano sostenible. Este reto requiere un buen funcionamiento del Poder Legislativo, a cuyo propósito se establece una serie de requisitos e incompatibilidades y prohibiciones para los diputados. Dentro de los requisitos están el de ser personas de notoria instrucción y honradez. Puesto que no se definen los componentes que configuran una "instrucción notoria", existe una total amplitud en lo relativo al nivel de preparación de los diputados, lo que se traduce en la designación de personas que no tienen la formación indispensable para contribuir apropiadamente a la tarea legislativa.

El fenómeno indicado apunta hacia la dificultad del Congreso de utilizar con efectividad legislativa los recursos humanos que lo conforman, puesto que un porcentaje considerable de ellos carecen de conocimientos que les permitan brindar aportes válidos; con efecto de ello, la carga del trabajo se concentra en un reducido número de diputados, cuyo rendimiento se relativiza por el cúmulo de responsabilidades asumidas, lo que les impone ocupar la mayor parte de su tiempo en reuniones, consultas y entrevistas, recortándoles el tiempo que requiere el estudio y producción normativa. A lo anterior se aúna la circunstancia de que la Asamblea no dispone suficientemente de equipos técnicos que suplan, en la medida requerida, la carencia que venimos de observar.

Otro aspecto del reto de gobernabilidad deriva del virtual pandemónium de leyes que existe, expresión que se emplea para calificar el hecho de que la labor legislativa ha producido centenares de cuerpos legales emitidos profusa y desordenadamente, pletóricos de reformas inconsistentes, con derogatorias expresas, tácitas o implícitas que causan un mundo de confusiones e inexactitudes interpretativas.

Otro aspecto digno de mencionarse es el del sentido partidarista prevaleciente, caracterizado por el hecho de que el interés particular de los partidos es trasladado a las respectivas fracciones, algunas veces en contraposición a los intereses generales, lo que afecta negativamente el producto del trabajo de los legisladores, que se ven atados a consignas y líneas, por encima de criterios mejor sustentados y de posiciones personales.

Además, se acusan casos de corrupción, oportunismo, inmoralidad y componendas deleznables en la pugna por el poder y los votos. Es decir, hay cuestionamientos de orden ético de mucha gravedad, que dañan la imagen del Congreso como un todo.

Puesto que la Asamblea Legislativa es un foro de alta resonancia ante la opinión pública, se presta a una utilización 
demagógica y teatral, en menoscabo de la bondad de la función. Ello incide en el desprestigio, en adición al provocado por los señalamientos de casos personales entre los mismos diputados. La observación sobre estos aspectos no desconoce que se producen normalmente en los parlamentos, en tanto foros políticos de debate, pero afecta la prosecución de negociaciones y la concertación de posiciones en aras del interés de la nación.

En resumen, el escenario interno en la Asamblea Legislativa y la amplísima exigencia técnica que requiere la función afectan la gobernabilidad democrática.

\section{Frente al reto del desarrollo humano sostenible}

La multiplicidad de facetas que demanda impulsar legislativamente la noción del desarrollo humano sostenible, demanda la producción de leyes enfocadas a la realización plena del ser humano, en sí y en sus potencialidades, lo cual está en la base del humanismo que sustenta y preconiza la Constitución. Este reto impone un profundo esfuerzo de revisión de la caótica normativa vigente, en especial la que se refiere a los aspectos del desarrollo humano sostenible. La ingente tarea técnica, por tanto, requiere coordinación con los otros órganos del Estado, cuya iniciativa de ley y requerimientos se ligan a la tarea de este poder público. La disposición constitucional que prescribe un orden económico que asegure a los habitantes del país una existencia digna del ser humano abarca, además del área normativa, el diseño y ejecución de políticas por el Ejecutivo.

En esta labor combinada un tema subyacente es el de las asignaciones presupuestarias, que aprueba la Asamblea Legislativa; de las que depende la posibilidad de las diferentes entidades estatales para llevar adelante sus programas y cumplir sus responsabilidades. La dificultad de la determinación de partidas en el presupuesto demanda atenciones y tiempos que no siempre se disponen en el congreso.

\section{Referentes hacia la seguridad ciudadana y jurídica}

Propiciar la seguridad ciudadana es una responsabilidad de la Asamblea Legislativa de orden crítico, que se aprecia tanto en lo que refiere a la necesidad de aprobar una legislación idónea, que establezca vías adecuadas para enfrentar este reto, como en lo relativo a sus atribuciones de elegir funcionarios, de recibir sus informes y de interpelarlos. En tal sentido, el tema de la seguridad es políticamente muy delicado y, además, es objeto de seguimiento en los medios de comunicación y por la opinión pública. Según reforma constitucional, las resoluciones de la Asamblea en cuanto a la destitución de jefes de seguridad pública o de inteligencia del Estado, por causa de graves violaciones de los derechos humanos, tienen carácter vinculante para la Presidencia de la República. Además, la Asamblea Legislativa está facultada para constituir comisiones especiales de investigación, cuyos resultados pueden aportar soluciones en este ámbito.

En materia de seguridad jurídica, el reto de gobernabilidad puede apreciarse en la absoluta necesidad de que se sistematice la legislación secundaria, de manera que su contenido sea coherente, apropiado, accesible y manejable; y que sea supervisado con efectividad en su aplicación. Es necesario que las personas conozcan sus derechos y los medios de asegurarlos y defenderlos, lo que no es viable si la legislación es difusa e inconsistente. Además, hay casos graves de preceptos constitucionales inexplicablemente no desarrollados en leyes secundarias, que hacen inviables derechos formalmente declarados, como es el caso de la prestación económica que están obligados a pagar los patronos a los trabajadores permanentes que renuncien a su trabajo, lo que genera incertidumbre sobre las posibilidades de obtener dicha prestación.

En resumen, la tarea de la Asamblea Legislativa en relación con el tema de la seguridad es amplia y multifacética, como reto de gobernabilidad.

\section{Marco de los derechos humanos}

La labor legislativa en el ámbito de los derechos humanos debe ser profusa, lo que nos impone hacer referencias ejemplificativas.

Así, se destaca en el ámbito de los derechos políticos la necesidad de disponer de una legislación electoral que asegure el debido ejercicio de estos derechos; que aseguren el respeto a la voluntad del pueblo y permitan que el proceso se desarrolle con agilidad y confiabilidad.

En relación con los derechos civiles, se destaca la importancia de que los recursos y procesos creados para su protección sean modernizados, vale decir, se necesita de una nueva ley de procedimientos constitucionales.

En materia de derechos económicos, sociales y culturales, la extensión del mandato es prácticamente inagotable, tanto en la creación como en el perfeccionamiento de los instrumentos legales que propendan a su efectividad $y$ desarrollo.

Paralelamente, a la Asamblea Legislativa le corresponde el estudio y ratificación de los tratados en esta materia, 
Ios cuales se producen abundantemente en foros internacionales, a escalas mundial y regional, representando un compromiso estatal el sometimiento de aquellos a la consideración del cuerpo legislativo. Por tanto, el reto legislativo implica el dominio técnico del derecho de los tratados y la consideración de cada uno de los convenios internacionales que introduzca el Órgano Ejecutivo para determinar su conveniencia nacional y resolver sobre su ratificación.

Cabría señalar la importancia de que la Asamblea Legislativa apoye el trabajo de la Procuraduría para la Defensa de Ios Derechos Humanos y, en general, de los ministerios y entidades que tienen responsabilidades en esta área; para el caso, mediante las asignaciones presupuestarias requeridas.

\section{Perspectivas de género y participación}

En lo relativo a la participación femenina en la Asamblea Legislativa, se señala que a partir de que se les confirió el derecho al voto, en 1939, pasaron casi cuatro cuatro décadas para que una mujer tuviera acceso al Poder Legislativo (revista ECA, marzo-abril 1997, página 264; artículo citado).

La Asamblea Legislativa es una institución en la que se observa, como en los otros órganos del Estado, una presencia diminuta de mujeres. Su escasa representación se liga a la tradicional discriminación de la mujer en esta sociedad. En la legislatura se ha alcanzado una ampliación del número de mujeres diputadas, sin embargo, en consonancia con el número de mujeres que conforman la población del país, que supera el $52 \%$, el número aún es bajo. Es de destacar el hecho de que representantes femeninas en el congreso han tenido importantes cargos, incluso la presidencia; y están jugando un papel descollante, pese a su reducido número.

En otra perspectiva, corresponde a la Asamblea Legislativa dictar normas que favorezcan la situación de la mujer en la sociedad, que continúa siendo de desigualdad, pese a la norma primaria, tratados y leyes que preconizan que no deben existir diferencias, que proscriben formalmente.

Es un hecho demostrado (ECA, mayo 1977, artículo "El mundo laboral de las mujeres en la microempresa" de Julia Evelyn Martínez, página 403) que la mujer, como propietaria o empleada de microempresas, y en general en la actividad económica del país, percibe un ingreso mensual promedio menor que el del hombre; que tiene menor cobertura en el sistema de seguridad social y que está casi marginada de la protección jurídica en las labores de domesticidad. En fin, el aporte de la mujer a la sociedad se ve restringido porque las oportunidades de desarrollo y participación son limitadas por razones de género.

\section{Situación actual}

La Asamblea Legislativa se presenta como un foro pluripartidista en el que se concentra el debate entre las principales fuerzas políticas ideológicas contrapuestas, $y$, por tanto, es un foro valiosísimo en el proceso de democratización, al consumarse dentro de él la apertura del sistema hacia todas las corrientes de opinión, superándose el período del anticomunismo férreo que cerraba cualquier válvula de manifestación disidente, así como favoreciendo la comunicación y el conocimiento entre unos y otros, antes apenas concebible.

El hecho de que los dos partidos mayoritarios no dispongan de la mayoría necesaria para tomar decisiones fundamentales ha generado la necesidad de mantener esfuerzos negociadores en busca de consensos, obteniéndose con muchas dificultades y hasta tardíamente. Este tipo de entrampamientos puede resultar paralizante o afectar la marcha normal de las tareas legislativas en perjuicio de la gobernabilidad democrática.

Asimismo, la necesidad de llegar a transacciones puede causar que las selecciones de funcionarios no sean las más felices o que se aprueben medidas legislativas de dudosa pertinencia técnica.

El hecho de que muchos de los institutos políticos hayan llevado como diputados a sus más connotados dirigentes ha elevado el nivel parlamentario y la opinión nacional de este órgano, el cual, con todo y sus avances democratizadores, tiene las limitaciones que antes reseñamos.

La participación ciudadana en la tarea legislativa es diminuta, tanto en el marco de la institución y sus comisiones como en cuanto al contacto de los particulares con los diputados.

\section{Desafíos}

I. Reforzar la competencia individual de los diputados mediante capacitación esmerada y continua, con el propósito de superar deficiencias y lograr mayores aportes personales. 
2. Incrementar el personal técnico de apoyo para agilizar y mejorar la producción legislativa.

3. Organizar trabajos de revisión de leyes con el objeto de proceder a una modernización del sistema y de superar la caótica situación existente.

4. Establecer reglas para efectuar las negociaciones interpartidarias o de fracciones, a fin de lograr concertaciones con mayor prontitud y favorecer la obtención de resultados tangibles.

5. Consultar y abrir canales de acceso a la participación ciudadana, individual y de organizaciones interesadas en los respectivos proyectos de ley.

6. Establecer canales de comunicación y consulta con los otros órganos del Estado, para la formulación de anteproyectos de leyes sobre temas prioritarios para promover el desarrollo humano sostenible, la seguridad jurídica y ciudadana y los derechos humanos en general.
7. Preconizar como eje de decisión la búsqueda de soluciones orientadas hacia el interés general de la nación, por encima de intereses partidaristas.

8. Erradicar prácticas y mecanismos de compromisos o de luchas intestinas reñidas con el impecable sentido ético que debe caracterizar la acción negociadora en el seno de la Asamblea.

9. Respetar irrefragablemente, por todas las fracciones legislativas, el derecho de cada uno de sus integrantes a disentir de las líneas partidistas y a exponer públicamente las razones de su particular opinión.

10. Fomentar la credibilidad en la Asamblea Legislativa y en el sistema democrático, identificando los grandes problemas del país para priorizar la dedicación de ese foro hacia la búsqueda de fórmulas para sus de plausibles soluciones, dictando leyes que favorezcan el desarrollo humano sostenible y superando exposiciones de carácter demagógico. 